\title{
Comparative Study on the Grain Refinement of Al-Si Alloy Solidified under the Impact of Pulsed Electric Current and Travelling Magnetic Field
}

\author{
Yunhu Zhang ${ }^{1, *}$, Xiangru Cheng ${ }^{1}$, Honggang Zhong ${ }^{1}$, Zhishuai $X{ }^{1}{ }^{1}$, Lijuan $\mathrm{Li}^{1}{ }^{1}$, \\ Yongyong Gong ${ }^{2}$, Xincheng Miao ${ }^{3}$, Changjiang Song ${ }^{1}$ and Qijie Zhai ${ }^{1}$ \\ 1 State Key Laboratory of Advanced Special Steels, Shanghai University, Shanghai 200072, China; \\ cxr16@shu.edu.cn (X.C.); hgzhong@shu.edu.cn (H.Z.); xzsshu@163.com (Z.X.); neullj@163.com (L.L.); \\ riversxiao@163.com (C.S.); qjzhai@shu.edu.cn (Q.Z.) \\ 2 College of Science, Shanghai University, Shanghai 200444, China; gyy@shu.edu.cn \\ 3 School of Materials Science and Engineering, University of Science and Technology Liaoning, \\ Liaoning 114051, China; miao-xincheng@hotmail.com \\ * Correspondence: zhangyunhu.zyh@163.com; Tel.: +86-21-56334042
}

Academic Editor: Hugo F. Lopez

Received: 10 May 2016; Accepted: 14 July 2016; Published: 20 July 2016

\begin{abstract}
It is high of commercial importance to generate the grain refinement in alloys during solidification by means of electromagnetic fields. Two typical patterns of electromagnetic fields, pulsed electric currents (ECP) and traveling magnetic field (TMF), are frequently employed to produce the finer equiaxed grains in solidifying alloys. Various mechanisms were proposed to understand the grain refinement in alloys caused by ECP and TMF. In this paper, a comparative study is carried out in the same solidification regime to investigate the grain refinement of Al-7 wt. \%Si alloy driven by ECP and TMF. Experimental results show that the application of ECP or TMF can cause the same grain refinement occurrence period, during which the refinement of primary $\mathrm{Al}$ continuously occurs. In addition, the related grain refinement mechanisms are reviewed and discussed, which shows the most likely one caused by ECP and TMF is the promoted dendrite fragmentation as the result of the ECP-induced or TMF-induced forced flow. It suggests that the same grain refinement process in alloys is provoked when ECP and TMF are applied in the same solidification regime, respectively.
\end{abstract}

Keywords: grain refinement; solidification; Al-Si alloys; pulsed electric current; traveling magnetic field

\section{Introduction}

High-performance structural alloys are urgently required in the automobile and aircraft industries. The application of high-performance structural alloys can reduce the weight of vehicles as well as the consumption of energy. In addition, the safety and stability of vehicles can be guaranteed or even promoted. Hence, the development of high-performance structural alloys has been paid much attention in the academic and industry worlds, especially for the development of high-performance iron, aluminum, magnesium and titanium alloys [1-4].

The high-performance structural alloys can be obtained by performing strengthening treatments, such as the solid-solution strengthening, precipitation strengthening, secondary phase strengthening, strain hardening, grain refinement and so on [5-7]. All these treatments can dramatically enhance the tensile strength of alloys. However, the plasticity of alloys can be deteriorated by most of these treatments, and only the grain refinement treatment can guarantee or even improve it [7]. Hence, much attention has been paid to achieving finer grain size in alloys. 
It has been frequently shown that significant grain refinement can be generated during the solidification process of alloys by applying two typical patterns of electromagnetic fields, pulsed electric current (ECP) [8-11] and electromagnetic stirring (EMS) [12-15]. ECP is conducted in alloys through electrodes directly contacting the melt, whereas EMS is a contactless method. Hence, the application of ECP or EMS in alloys is regarded as two different approaches to generate finer grains. Various mechanisms were also proposed to explain the grain refinement in alloys caused by ECP or EMS. The mechanisms proposed to understand the ECP-induced grain refinement include the heterogeneous nucleation mechanism that the nucleation rate is promoted owing to the raised undercooling [16,17], the dendrite fragmentation mechanism that the dendrite arms' detachment is caused by the generated pulsed Joule heating [18,19] and Lorenz force [20], and so on. As for EMS, the forced flow-induced dendrite fragmentation is almost accepted as the grain refinement mechanism [13].

Little attention has been paid to directly comparing the grain refinement generated by ECP or EMS in alloys, although both of them have been intensively investigated. Our recent research has shown that the Lorentz force caused by ECP and its own induced magnetic field can induce the strong forced flow inside melt $[21,22]$, which was also the key effect that caused the grain refinement in alloy [22,23]. Since it is well known that grain refinement under the application of EMS is caused by the forced flow, it indicates that ECP or EMS may cause the same grain refinement process in alloys. Hence, in the present paper, the traveling magnetic field (TMF) as one typical pattern of EMS is employed to be compared with ECP in the same solidification regime.

\section{Materials and Methods}

\subsection{Al-7 wt. \%Si Preparation}

The Al-7 wt. \%Si hypoeutectic alloy (nominal composition) was prepared by melting pure Al (99.99 wt. \%) and Si (99.999 wt. \%) and modified by Sr of 200 ppm in a clay-graphite crucible. In order to prepare ingots for solidification experiments, the molten Al-7 wt. \%Si alloy was poured into a cylindrical stainless steel mold of $50 \mathrm{~mm}$ diameter and cooled to the room temperature. The cooled samples were cut to the same weight of $310 \mathrm{~g}$ to make each sample having a same geometry (50 $\mathrm{mm}$ (diameter) $\times 60 \mathrm{~mm}$ (height)).

\subsection{Solidification Experiment Procedures}

The preparatory samples for solidification experiments were re-melted in a double-walled cylindrical stainless steel mold with an inner-diameter of $50 \mathrm{~mm}$ (see Figure 1). In order to sufficiently remelt the samples, their temperature was heated up to $750{ }^{\circ} \mathrm{C}$ in a resistance furnace (Carbolite, Gpc 1300) and kept constant for $45 \mathrm{~min}$, and then deceased to $720{ }^{\circ} \mathrm{C}$ and kept for another $30 \mathrm{~min}$. After that, the mold with the melt was taken from the furnace. Then, both NiCr-Ni thermocouples and two parallel cylindrical stainless steel electrodes, fixed at a steel lid, were inserted into the melt through the free surface. Finally, the mold was cooled in air. ECP or TMF was applied during different stages of the cooling process to investigate the efficient grain refinement formation period.

The inner-wall of the mold was coated by an electrically insulating material (BN) to suppress the electric current flowing into the mold and protect the steel mold from the corrosion of the high temperature melt. The thermocouples were located at the different heights along the vertical direction in the center of samples. Each thermocouple was embedded in an INCONEL (trademark of INCO Alloys International, Huntington, WV, USA) sheath with an outer diameter of $1.5 \mathrm{~mm}$ and covered by $\mathrm{Al}_{2} \mathrm{O}_{3}$ tubes for protecting. The monitor frequency, resolution and error of the temperature measurement were $5 \mathrm{~Hz}, 0.01^{\circ} \mathrm{C}$ and $\pm 1{ }^{\circ} \mathrm{C}$, respectively. The two parallel cylindrical electrodes having a diameter of $8 \mathrm{~mm}$ were symmetrically positioned at the diameter of mold with a distance of $36 \mathrm{~mm}$ and immersed into the melt with a depth of $10 \mathrm{~mm}$. The lateral surface of the electrodes was coated by BN to confine the electric current only through the front surface of the electrodes into the melt. A rectangular pulsed electric current (see Figure 2) was generated by a power supply pe86CWD 
(plating electronic). The employed electric current parameters were $480 \mathrm{~A}\left(I_{0}\right), 200 \mathrm{~Hz}(f)$ and $0.5 \mathrm{~ms}$ $\left(t_{p}\right) . I_{0}$ is the current intensity, $f$ is the frequency and $t_{p}$ is the pulse length. TMF was supplied by COMMA (COMbined Magnetic field) facility of HZDR. The employed strength and traveling direction of employed TMF were $10 \mathrm{mT}$ and downward, respectively. More details with respect to this magnetic field setup can be found in [13].

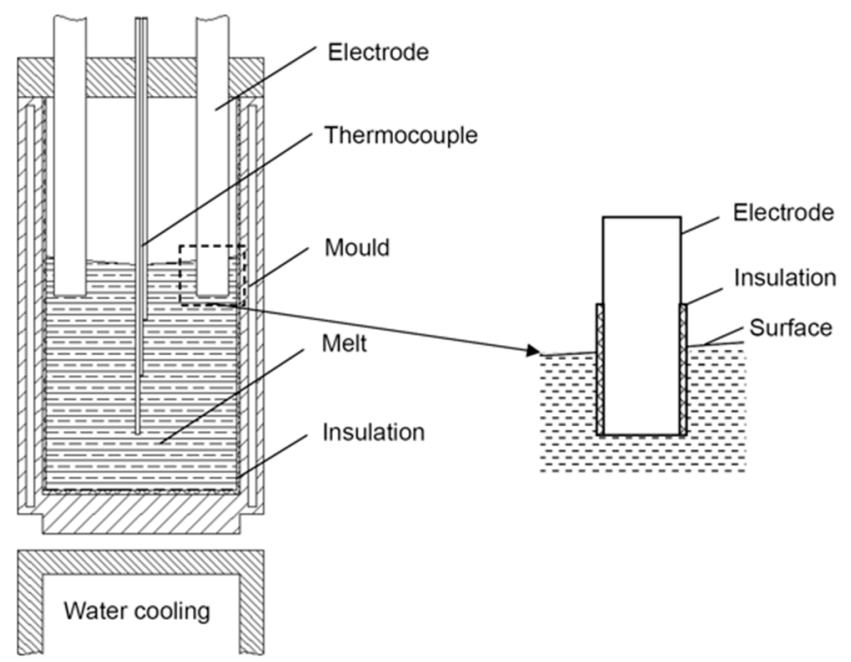

Figure 1. Schematic drawing of the experimental setup.

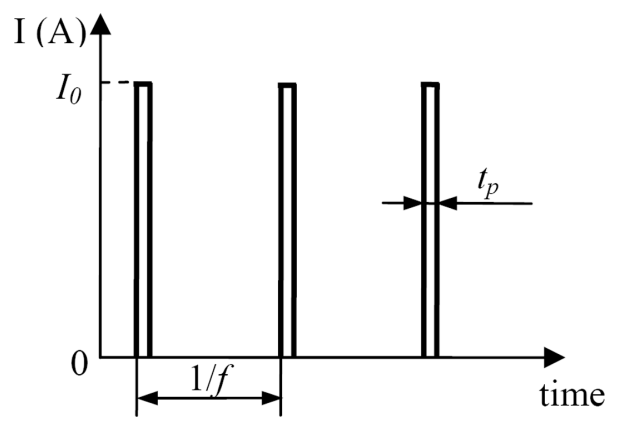

Figure 2. Schematic drawing of the pulsed electric current.

As mentioned previously, our aim is to compare the grain refinement process in solidified alloys under the application of ECP or TMF. In order to guarantee the comparability, the double-walled mold was employed and cooled in air to solidify the sample. However, it is necessary to examine whether the application of such kind of mold and cooling condition can achieve a same solidification regime in samples under the influence of ECP or TMF. Figure 3 presents the measured cooling curves of Al-7 wt. \%Si alloy under the application of ECP or TMF. It is evident that the almost same temperature field and cooling history can be observed in both of samples. It means that the application of such kind of mold and cooling condition can realize the same solidification regime and convincingly guarantee the comparability. 


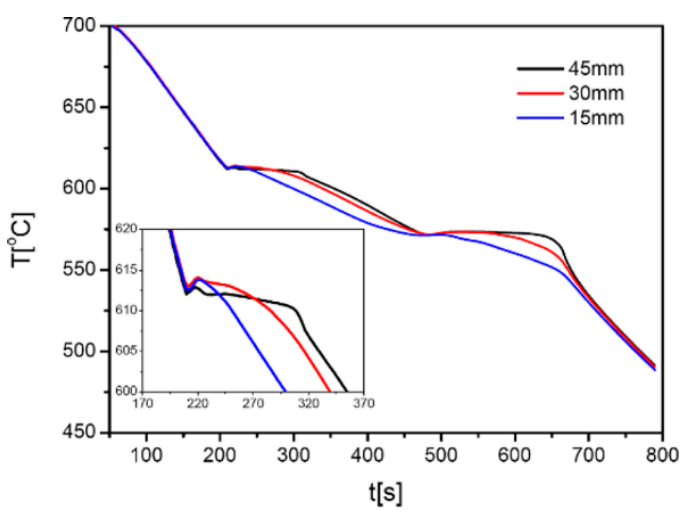

(a)

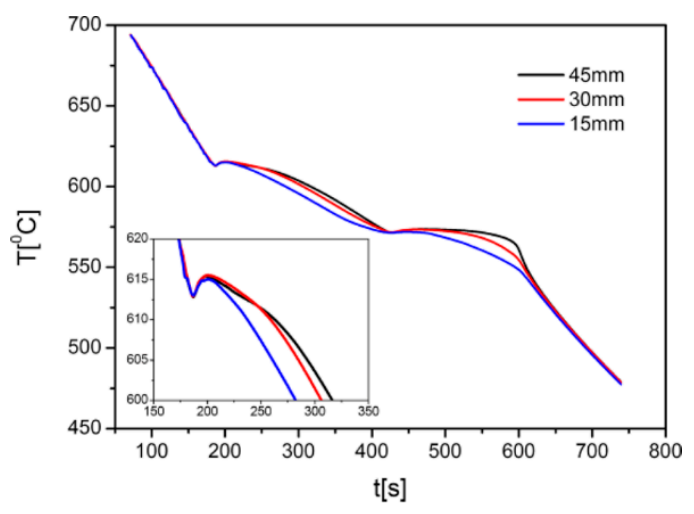

(b)

Figure 3. Cooling curves of Al-7 wt. \%Si alloy solidified in the double-walled mold: (a) with ECP; (b) with TMF.

\subsection{Metallography}

The as-solidified samples for metallographic analysis were longitudinally sectioned along a plane that is perpendicular to the plane containing the two parallel electrodes. One section was ground on $\mathrm{SiC}$ paper, etched in a solution of $60 \mathrm{~mL} \mathrm{HCl}, 30 \mathrm{~mL} \mathrm{HNO}_{3}, 5 \mathrm{~mL} \mathrm{HF}$, and $5 \mathrm{~mL} \mathrm{H}_{2} \mathrm{O}$, and directly taken a photo via a digital camera (Konica Minolta, Tokyo, Japan) for the macrostructure analysis. Another corresponding section was employed for the quantitative analysis of grain size. It was ground on $\mathrm{SiC}$ paper and polished from $6 \mu \mathrm{m}$ to $1 \mu \mathrm{m}$, electro-etched in Barker etching reagent at $25 \mathrm{~V}, 15 \mathrm{~Hz}$ for $180 \mathrm{~s}$, then photographed by an optical microscope MeF4 (Leica Microsystems, Wetzlar, Germany) with the polarized light. The obtained picture covering the whole sample was used to measure the grain size by the linear intercept method in a software package aquinto a4i (Fa. Aquinto AG). The grain size with measuring error of $\pm 0.08 \mathrm{~mm}$ was estimated by performing the measurement in the same sample four times.

\section{Results and Discussion}

\subsection{Solidified Structure}

The intention of this paper was to compare the grain refinement formed in Al-Si alloy under the application of ECP and TMF. In order to make a reference, a sample was solidified without the influence of external energy fields first. Figure 4 presents the corresponding macrostructure in the longitudinal section. It can be seen that a few numbers of coarse equiaxed grains with a mean grain size of $2.82 \mathrm{~mm}$ (see Table 1) solidified in the referenced sample.

Figure 5 shows macrostructures of the solidified Al-7 wt. \%Si alloy under the application of ECP. In an attempt to investigate the efficient grain refinement formation period, the electric current was applied during two different solidification stages. One is applied from the initial cooling of the sample (about $700{ }^{\circ} \mathrm{C}$ ) until the sample is totally solidified, while another starts at the initial cooling and stops just after the recalescence is completed. Figure $5 \mathrm{a}, \mathrm{b}$ display the corresponding macrostructures in the longitudinal section of samples. Both of them present really similar solidified macrostructures with a significantly reduced grain size among the range of $0.8 \sim 0.9 \mathrm{~mm}$ (see Table 1). In view of the fact that ECP was powered off when the recalescence in the sample of Figure $5 b$ was completed, it suggests that the refinement of primary $\mathrm{Al}$ mainly generates during the initial solidification period that is composed of the nucleation period and recalescence period. 


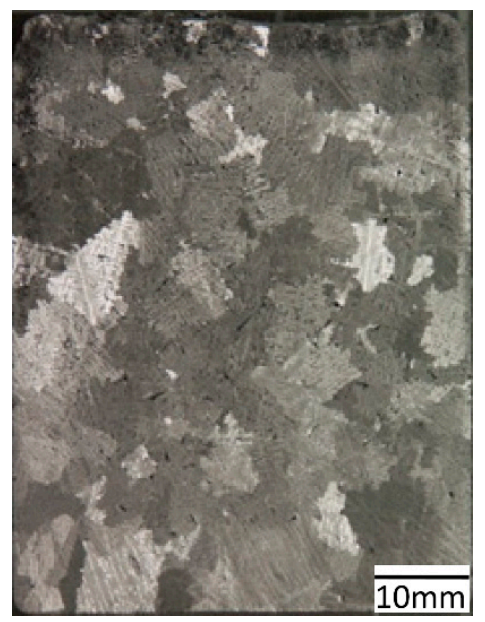

Figure 4. Macrostructure of the solidified Al-7 wt. \%Si alloy in longitudinal section without external energy fields.

Table 1. Influence of the applied pulsed electric currents (ECP) and traveling magnetic field (TMF) on the grain size.

\begin{tabular}{cccccccc}
\hline Figure & $\mathbf{4}$ & $\mathbf{5 a}$ & $\mathbf{5 b}$ & $\mathbf{5 c}$ & $\mathbf{6 a}$ & $\mathbf{6 b}$ & $\mathbf{6 c}$ \\
\hline Mean grain size $(\mathrm{mm})$ & 2.82 & 0.84 & 0.88 & 2.12 & 1.06 & 1.01 & 1.98 \\
\hline
\end{tabular}

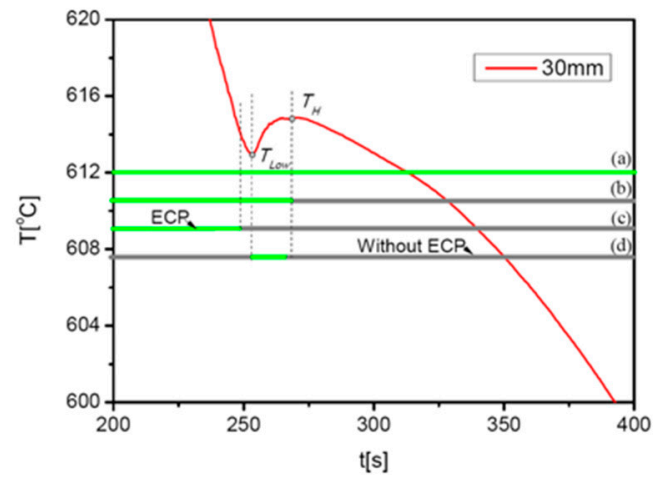

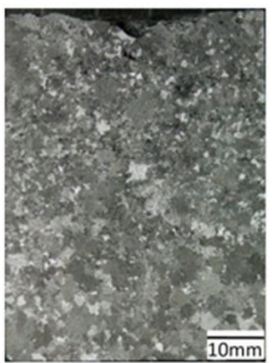

(a)

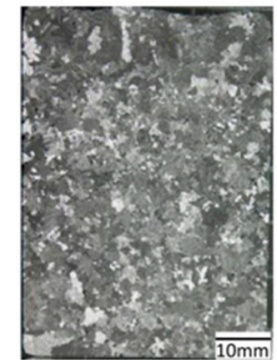

(b)

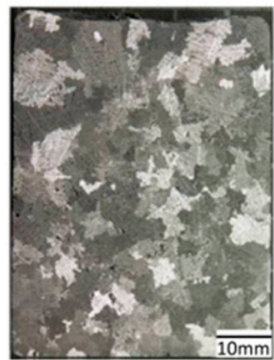

(c)

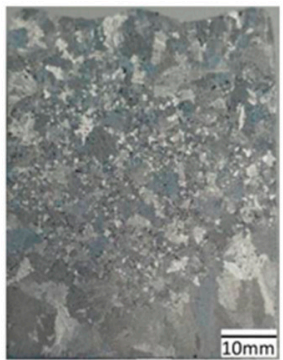

(d)

Figure 5. Influence of ECP application time on the longitudinal section macrostructure of the solidified Al-7 wt. \%Si alloy: (a-d) correspond to the various application time shown in the schematic view (green line: turn on ECP; grey line: turn off ECP).

In order to examine the evolution of grain size during the initial period, ECP was applied during the nucleation and recalescence period, respectively. Figure $5 \mathrm{c}$ presents macrostructures of samples treated by ECP during the nucleation period. It can be observed that the macrostructure of samples 
is refined when the ECP stopping time is close to the occurrence of recalescence. The corresponding measured mean grain size decreased to $2.12 \mathrm{~mm}$ (see Table 1). However, it should be noted that although the finer grains are generated, the grain size is still larger than that in Figure 5a,b. It suggests that grain refinement still continuously occurs during the recalescence period. Figure $5 \mathrm{f}$ displays the macrostructure of the sample treated by ECP only during the recalescence period. It can be seen that grain refinement occurs in view of many tiny grains generated.

Similar to the solidification experiments with ECP, TMF was applied, respectively, during different solidification periods including the whole solidification period, the initial solidification period, the nucleation period and the recalescence period. The corresponding macrostructures on the longitudinal section of solidified Al-7 wt. \%Si samples are presented in Figure 6. In comparison with the reference sample shown in Figure 4, a significant grain refinement occurs by applying TMF from the initial cooling of the sample (about $700^{\circ} \mathrm{C}$ ) until it is totally solidified or just after the recalescence is completed (see Figure 6a,b). A similar macrostructure is achieved with almost the same grain size of about $1 \mathrm{~mm}$ (see Table 1). It implies that the grain refinement caused by TMF is also mainly achieved during the initial solidification period. Figure $6 c$ presents the macrostructure under the treatment of TMF during the nucleation period. The finer equiaxed grains with a grain size of about $2 \mathrm{~mm}$ can be observed in the sample, but the grain size is still larger than that in Figure 6a,b. Figure $6 \mathrm{~d}$ shows that the tiny grains are produced when TMF is only applied during the recalescence period. It suggests that the grain refinement also continuously occurs during the nucleation period and recalescence period.

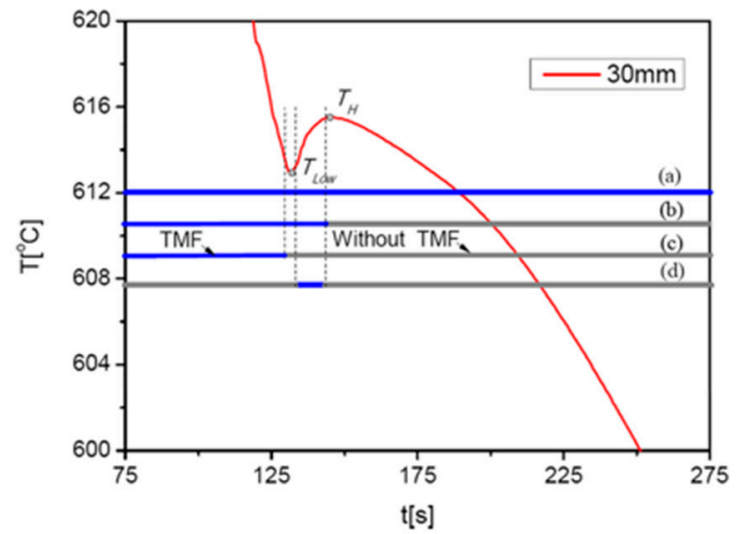

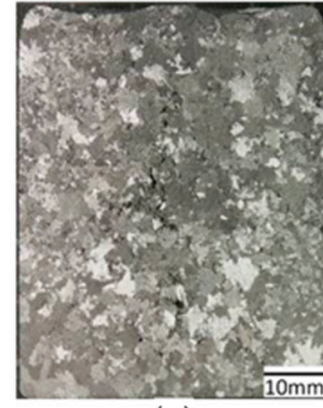

(a)

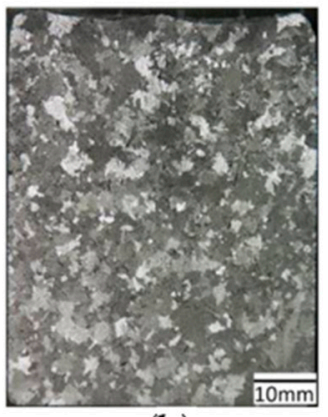

(b)

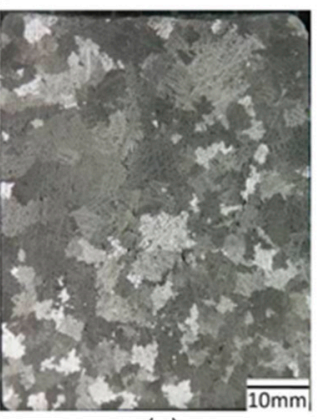

(c)

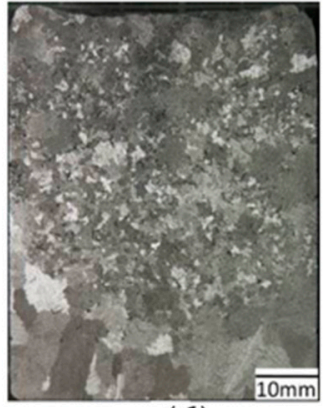

(d)

Figure 6. Influence of the various TMF (10 $\mathrm{mT}$, downward) application time on the longitudinal section macrostructure of the solidified Al-7 wt. \%Si alloy: (a-d) correspond to the various application times shown in the schematic view (blue line: turn on TMF; grey line: turn off TMF).

In summary, it is clear that the grain refinement driven by ECP and TMF in the employed solidification regime has the same grain refinement occurrence period, during which the refined equiaxed grains are continuously generated. It could be due to the fact that the ECP- or TMF-induced forced flow plays a key role in the grain refinement of alloys $[13,22]$. According to the fluid mechanics theory [24], any convection can be effectively damped by the high viscosity. During the solidification 
process, the viscosity in the melt gradually increases as the solid phase is continuously precipitated from the melt. It is evident that the ECP or TMF application cannot create a substantial melt flow when the solid fraction in the sample becomes too large. Hence, it is logical to explain that the grain refinement occurs only during the initial solidification period under the influence of both ECP and TMF. Moreover, it has been demonstrated for the first time that grain refinement also occurs during the recalescence period, whereas the previous research reported that grain refinement only occurs during the nucleation period [9].

\subsection{Grain Refinement Mechanism}

In order to unlock the grain refinement mechanism, we should consider and understand the origin and survival of grains during solidification, because the final grain size mainly depends on these two factors. In our case, the survival of grains can be guaranteed on account of the fact that a thermal homogenization inside the melt was generated during the initial solidification period under the application of ECP and TMF (see Figure 3). Hence, in the present paper, the origin of grains is the main focus.

Two origins of equiaxed grains for the grain refinement caused by electric currents and electromagnetic stirring have been frequently proposed: that the formed nuclei is the result of the promoted heterogeneous nucleation [16,17], and dendrite fragmentation $[10,13,20]$. According to the classical nucleation theory [25], heterogeneous nucleation can be promoted if the deeper undercooling is achieved. It has been proposed that the maximum undercooling can be raised to accelerate the heterogeneous nucleation rate [17]. Hence, the influence of ECP and TMF on the maximum undercooling is clarified in our configuration.

The maximum undercooling $\Delta T$ is defined as the difference between the liquidus $T_{L}$ and the lowest temperature point $T_{\text {Low }}$ before recalescence occurs $\left(\Delta T=T_{L}-T_{\text {Low }}\right.$, see Figure 7$)$ [25]. It has been reported that the value of maximum undercooling can be influenced by the cooling rate of alloys in liquid state [26]. Hence, it is necessary to set both of the samples with and without the application of external energy fields at the same cooling rate. Figure 8 displays the cooling curves at the core axis with a height of $30 \mathrm{~mm}$ measured in the Al-7 wt. \%Si alloy with and without the influence of ECP and TMF. Fortunately, it can be seen that almost the same cooling rate and history were achieved in the Al-7 wt. \%Si alloy regardless of the application of ECP and TMF. Hence, the effect of ECP and TMF on the maximum undercooling can be investigated convincingly by comparing the cooling curves.

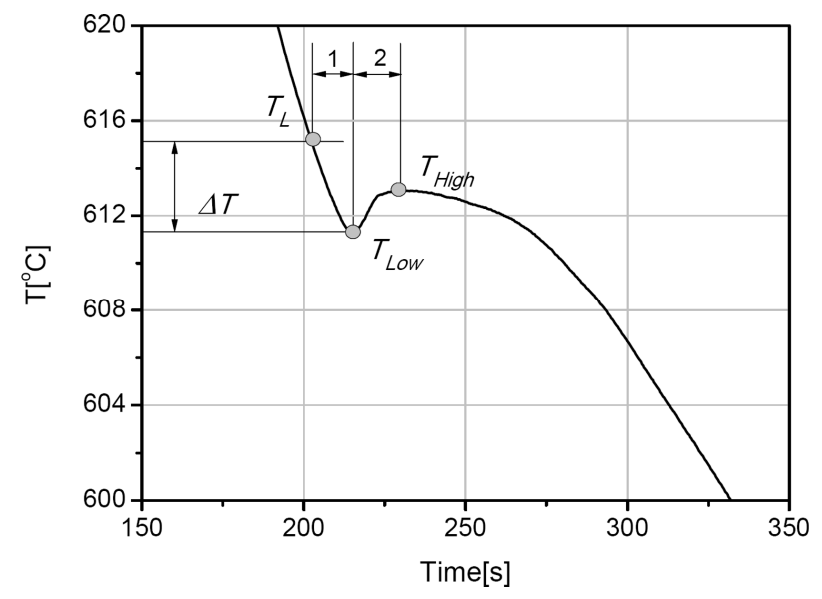

Figure 7. Schematic view of a cooling curve during the initial solidification. $T_{L}$ : liquidus of sample, $T_{\text {Low }}$ : lowest point before recalescence, $T_{\text {High }}$ : highest point after recalescence, $\Delta T$ : maximum undercooling, 1: nucleation period, 2: recalescence period. 


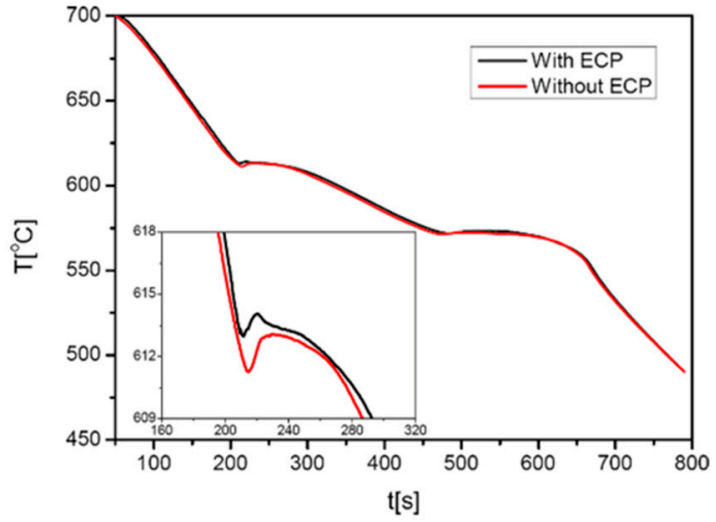

(a)

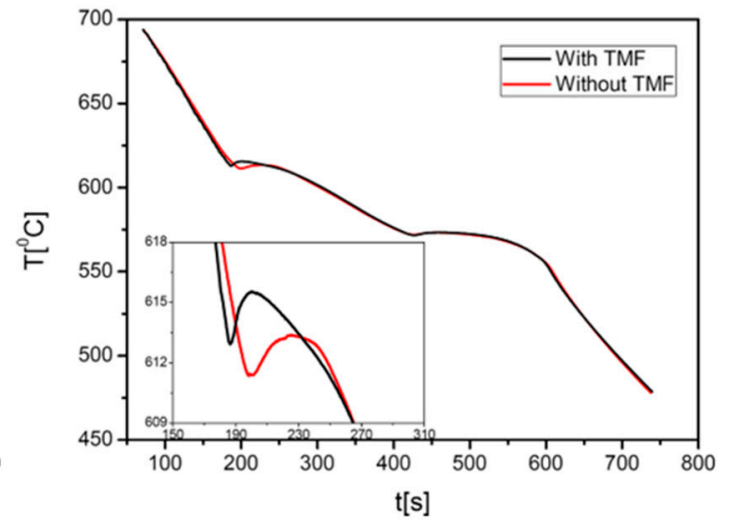

(b)

Figure 8. Cooling curves of the solidified Al-7 wt. \%Si alloy measured at the height of $30 \mathrm{~mm}$ : (a) ECP; (b) TMF.

As shown in Figure 8, the $T_{\text {Low }}$ is increased under the applied ECP or TMF. The measured $T_{\text {Low }}$ for the sample without external energy fields was $611.3^{\circ} \mathrm{C}$, whereas for the sample treated by ECP and TMF it was $612.9^{\circ} \mathrm{C}$ and $613.0^{\circ} \mathrm{C}$, respectively (see Table 2). It should be noted here that although the temperature measurement error of the employed thermocouples is as high as $\pm 1^{\circ} \mathrm{C}$, only the repeatability error of the thermocouple having a value of $\pm 0.1^{\circ} \mathrm{C}$ based on four measurements is considered here because the same thermocouple was employed in the solidification experiments. Hence, it can fully identify that the value of $T_{\text {Low }}$ is increased under the application of ECP or TMF. Since the $T_{L}$ is constant for the alloy with a determined composition, the maximum undercooling only depends on the value of $T_{\text {Low }}$ with the relationship of $\Delta T=T_{L}-T_{\text {Low }}$. It indicates that the maximum undercooling $\Delta T$ is reduced under the influence the ECP and TMF. However, the significant grain refinement remains achieved, as shown in Figures 5 and 6. It means that our experimental results do not confirm the previously proposed origin of refined grains, which states that the formed nuclei are due to the raised maximum undercooling.

Table 2. Influence of the applied ECP and TMF on the $T_{\text {Low }}$ of Al-7 wt. \%Si alloy.

\begin{tabular}{cccc}
\hline Conditions & Without ECP/TMF & ECP & TMF \\
\hline$T_{\text {Low }}\left({ }^{\circ} \mathrm{C}\right)$ & 611.3 & 612.9 & 613.0 \\
\hline
\end{tabular}

Hence, it is more likely that the main origin for grain refinement under the application of ECP and TMF is the dendrite fragmentation promoted by the ECP-induced or TMF-induced forced flow. Recent investigations [27] have theoretically shown that the forced flow can induce solute enrichment at the root of dendrite arms to cause the dendrite arms' remelting. In our case, it is possible that the forced flow can trigger the remelting of high-order dendrite arms to detach from the dendrite trunk due to the forced flow-induced solute fluctuation as schematically shown in Figure 9. The detached dendrite arms would be subsequently transported out as new potential nuclei sites under the influence of forced flow. Since the size of dendrite arms is really less than the maternal dendrite, numerous tiny grains mixed with some larger grains are consequently formed as shown in Figure 10. 


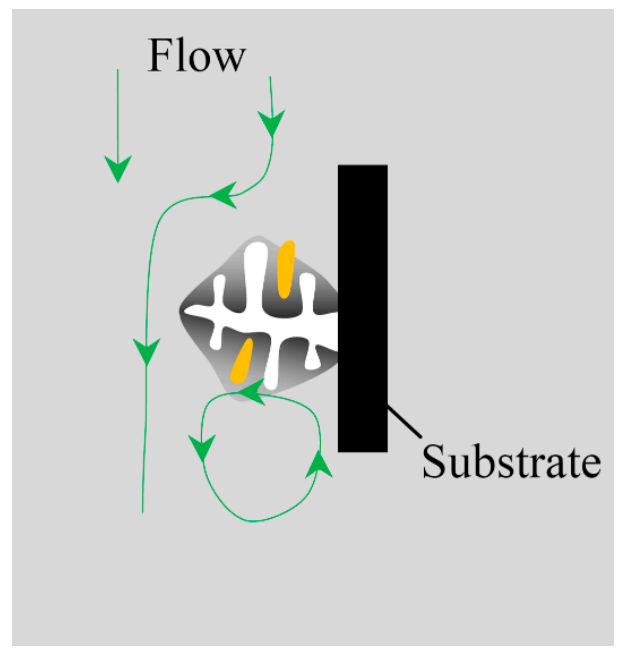

Figure 9. Schematic view of the high-order dendrite arms detachment under the forced flow (yellow: detached dendrite arms).

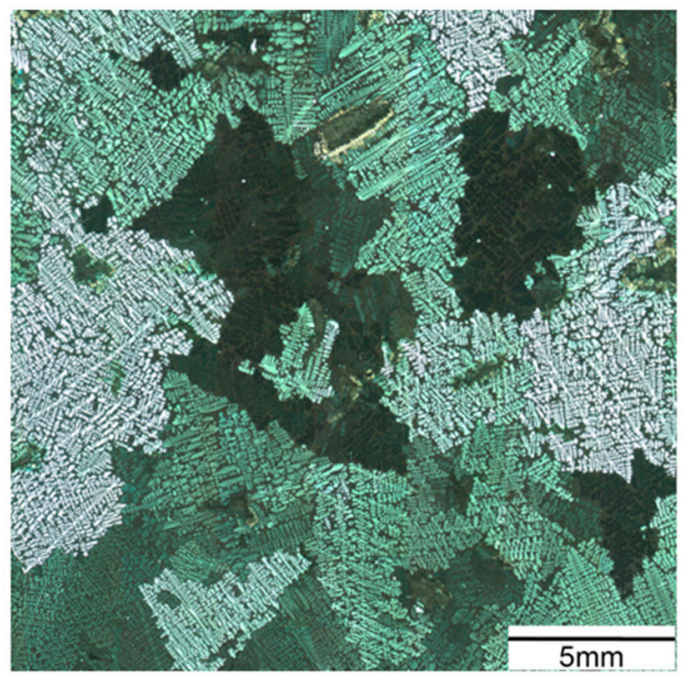

(a)

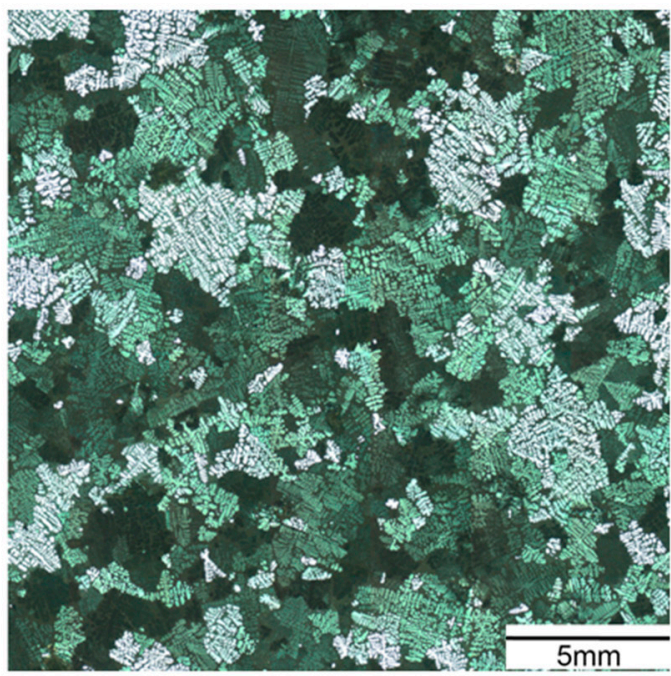

(b)

Figure 10. Macrostructures in the longitudinal section observed by microscope with polarized light: (a) without ECP (see Figure 4); (b) with ECP (see Figure 5b).

Actually, this grain multiplication process can be used to understand the reduction of maximum undercooling caused by ECP and TMF in our case. According to the free growth theory, which is suitable to our solidification regime [28], the recalescence is triggered when the temperature of the melt in the $\mathrm{n}+1$ th time interval $\left(T_{n+1}\right)$ is higher than the nth interval $\left(T_{n}\right)$ which equals the $T_{\text {Low }}$. The relationship between the $T_{n+1}$ and $T_{n}$ during the solidification process is given by

$$
T_{n+1}-T_{n}=\frac{q_{\text {total }}}{C_{p V}}-R \mathrm{~d} t
$$

where $R$ is the imposed cooling rate, $t$ is the time, $q_{\text {total }}$ is the releasing latent heat from the growing crystals and $C_{p V}$ is the specific heat of the melt per unit volume. As the undercooling is gradually increasing, the forced flow induced-by ECP and TMF generates more nuclei that release more latent heat $\left(q_{\text {total }}\right)$ to defend the cooling of the melt, eventually raising the $T_{\text {Low }}$ as well as causing the maximum undercooling reduction. 
In summary, based on our experimental results and discussion, it is evident that the grain refinement process driven by ECP or TMF is almost the same in the employed solidification regime on account of the fact that their application can cause the same grain refinement occurrence period and the same origins of equiaxed grains. The gained knowledge provides more insights into understanding grain refinement under the influence of electromagnetic fields.

\section{Conclusions}

In the present paper, the grain refinement in Al-7 wt. \%Si alloy driven by ECP and TMF was comparatively studied by performing a series of solidification experiments that focused on the grain refinement occurrence period and the origins of finer equiaxed grains. Three conclusions are listed as follows:

(1) The grain refinement occurrence period for the application of ECP and TMF is the initial solidification period that is composed of the nucleation period and recalescence period, during which the grain size reduction continuously occurs.

(2) The main origins of finer equiaxed grains driven by ECP and TMF would be the forced flow promoted dendrite fragmentation.

(3) The results suggest that ECP and TMF provoke the same grain refinement process in Al-7 wt. \%Si alloy when the same solidification regime is employed.

Acknowledgments: The authors acknowledge the financial supports from the National Natural Science Foundation of China (Grant No. 51320105003, 51404150, 51227803), the financial support from the National Basic Research Program of China (973 program, granted No. 2011CB012902), and the Science and Technology Commission of Shanghai Municipality (granted No. 14DZ2261200). Yunhu Zhang would like to sincerely thank Sven Eckert and Dirk Räbiger from the "Helmholtz-Zentrum Dresden-Rossendorf (HZDR)" for the fruitful discussions and the support during the implementation.

Author Contributions: Yunhu Zhang, Changjiang Song and Qijie Zhai conceived and designed the experiments; Yunhu Zhang, Xiangru Cheng, Honggang Zhong Zhishuai Xu and Lijuan Li performed the solidification experiments and grain size measurements; Yunhu Zhang, YongYong Gong and Xincheng Miao analyzed the results and fostered the interpretation; all authors contributed equally to the discussion and writing the paper.

Conflicts of Interest: The authors declare no conflict of interest.

\section{Abbreviations}

The following abbreviations are used in this manuscript:

ECP Pulsed electric currents

TMF Traveling magnetic field

EMS Electromagnetic stirring

\section{References}

1. Grassel, O.; Kruger, L.; Frommeyer, G.; Meyer, L.W. High strength Fe-Mn-(Al, Si) TRIP/TWIP steels development-properties-application. Int. J. Plast. 2000, 16, 1391-1409. [CrossRef]

2. Williams, J.C.; Starke, E.A., Jr. Progress in structural materials for aerospace systems. Acta Mater. 2003, 51, 5775-5799. [CrossRef]

3. Jiang, J.; Zhang, F.; Ma, A.; Song, D.; Chen, J.; Liu, H.; Qiang, M. Biodegradable Behaviors of Ultrafine-Grained ZE41A Magnesium alloy in DMEM Solution. Metals 2015, 6, 365-369. [CrossRef]

4. Ma, A.; Zhu, C.; Chen, J.; Jiang, J.; Song, D.; Ni, S.; He, Q. Grain Refinement and high-performance of equal-channel angular pressed Cu-Mg Alloy for electrical contact wire. Metals 2014, 4, 586-596. [CrossRef]

5. Gong, J.C.; Wilkinson, A.J. A microcantilever investigation of size effect, solid-solution strengthening and second-phase strengthening for <a> prism slip in alpha-Ti. Acta Mater. 2011, 59, 5970-5981. [CrossRef]

6. Seidman, D.N.; Marquis, E.A.; Dunand, D.C. Precipitation strengthening at ambient and elevated temperatures of heat-treatable Al (Sc) alloys. Acta Mater. 2002, 50, 4021-4035. [CrossRef]

7. Murty, B.S.; Kori, S.A.; Chakraborty, M. Grain refinement of aluminium and its alloys by heterogeneous nucleation and alloying. Int. Mater. Rev. 2002, 47, 3-29. [CrossRef] 
8. Li, J.; Ma, J.H.; Gao, Y.L.; Zhai, Q.J. Research on solidification structure refinement of pure aluminum by electric current pulse with parallel electrodes. Mater. Sci. Eng. A 2008, 490, 452-456. [CrossRef]

9. Liao, X.L.; Zhai, Q.J.; Luo, J.; Chen, W.J.; Gong, Y.Y. Refining mechanism of the electric current pulse on the solidification structure of pure aluminum. Acta Mater. 2007, 55, 3103-3109. [CrossRef]

10. Gao, M.; He, G.H.; Yang, F.; Guo, J.D.; Yuan, Z.X.; Zhou, B.L. Effect of electric current pulse on tensile strength and elongation of casting ZA27 alloy. Mater. Sci. Eng. A 2002, 337, 110-114. [CrossRef]

11. Zhang, Y.; Song, C.; Zhu, L.; Zheng, H.; Zhong, H.; Han, Q.; Zhai, Q. Influence of electric-current pulse treatment on the formation of regular eutectic morphology in an Al-Si eutectic Alloy. Metall. Mater. Trans. B 2011, 42, 604-611. [CrossRef]

12. Griffiths, W.D.; McCartney, D.G. The effect of electromagnetic stirring during solidification on the structure of Al-Si alloys. Mater. Sci. Eng. A 1996, 216, 47-60. [CrossRef]

13. Metan, V.; Eigenfeld, K.; Räbiger, D.; Leonhardt, M.; Eckert, S. Grain size control in Al-Si alloys by grain refinement and electromagnetic stirring. J. Alloy. Compd. 2009, 487, 163-172. [CrossRef]

14. Gong, Y.Y.; Luo, J.; Jing, J.X.; Xia, Z.Q.; Zhai, Q.J. Structure refinement of pure aluminum by pulse magneto-oscillation. Mater. Sci. Eng. A 2008, 497, 147-152. [CrossRef]

15. Willers, B.; Eckert, S.; Nikrityuk, P.A.; Räbiger, D.; Dong, J.; Eckert, K.; Gerbeth, G. Efficient Melt Stirring Using Pulse Sequences of a Rotating Magnetic Field: Part II. Application to Solidification of Al-Si Alloys. Metall. Mater. Trans. B 2008, 39, 304-316. [CrossRef]

16. Zhao, Z.; Wang, J.; Liu, L. Grain Refinement by Pulse Electric Discharging and Undercooling Mechanism. Mater. Manuf. Process. 2011, 26, 249-254. [CrossRef]

17. Barnak, J.P.; Sprecher, A.F.; Conrad, H. Colony (grain) size reduction in eutectic Pb-Sn castings by electroplusing. Scr. Metall. Mater. 1995, 32, 879-884. [CrossRef]

18. Yin, Z.X.; Liang, D.; Chen, Y.E.; Cheng, Y.F.; Zhai, Q.J. Effect of electrodes and thermal insulators on grain refinement by electric current pulse. Trans. Nonferr. Met. Soc. China 2013, 23, 92-97. [CrossRef]

19. Yang, Y.S.; Zhou, Q.; Hu, Z.Q. The influence of electric current pulses on the microstructure of magnesium alloy AZ91D. Mater. Sci. Forum 2005, 488, 201-204. [CrossRef]

20. Nakada, M.; Shiohara, Y.; Flemings, M.C. Modification of solidification structures by pulse electric discharging. ISIJ Int. 1990, 30, 27-33. [CrossRef]

21. Zhang, Y.; Miao, X.; Shen, Z.; Han, Q.; Song, C.; Zhai, Q. Macro segregation formation mechanism of the primary silicon phase in directionally solidified Al-Si hypereutectic alloys under the impact of electric currents. Acta Mater. 2015, 97, 357-366. [CrossRef]

22. Räbiger, D.; Zhang, Y.; Galindo, V.; Franke, S.; Willers, B.; Eckert, S. The relevance of melt convection to grain refinement in Al-Si alloys solidified under the impact of electric currents. Acta Mater. 2014, 79, 327-338. [CrossRef]

23. Zhang, Y.; Räbiger, D.; Eckert, S. Solidification of pure aluminium affected by a pulsed electrical field and electromagnetic stirring. J. Mater. Sci. 2016, 51, 2153-2159. [CrossRef]

24. Davidson, P.A. An Introduction to Magnetohydrodynamic; Cambridge University Press: Cambridge, UK, 2001.

25. Kurz, W.; Fisher, D.J. Fundamentals of Solidification; Trans Tech Publications: Pfaffikon, Switzerland, 1986.

26. Gowri, S.; Samuel, F.H. Effect of cooling rate on the solidification. Metall. Trans. A 1992, 23, 3369-3376. [CrossRef]

27. Campanella, T.; Charbon, C.; Rappaz, M. Grain refinement induced by electromagnetic stirring: A dendrite fragmentation criterion. Metall. Mater. Trans. A 2004, 35, 3201-3210. [CrossRef]

28. Greer, A.; Bunn, A.; Tronche, A.; Evans, P.; Bristow, D. Modelling of inoculation of metallic melts: Application to grain refinement of aluminium by Al-Ti-B. Acta Mater. 2000, 48, 2823-2835. [CrossRef]

(c) 2016 by the authors; licensee MDPI, Basel, Switzerland. This article is an open access article distributed under the terms and conditions of the Creative Commons Attribution (CC-BY) license (http://creativecommons.org/licenses/by/4.0/). 